\title{
La Unión Europea y la lucha contra el fraude
}

\author{
Margarita Navarro Pabsdorf \\ Eduardo Cuenca García \\ Universidad de Granada
}

\section{Resumen}

El presente trabajo plantea los retos de la Unión Europea en la lucha contra el fraude fiscal. Aunque este objetivo se viene persiguiendo desde hace años, la creación de la Oficina Europea de Lucha contra el Fraude (OLAF) en 1999 y las mayores necesidades de los presupuestos para poder contrarrestar los efectos de la crisis económica actual, han intensificado los esfuerzos para mejorar los mecanismos de control, promover la cooperación entre los Estados miembros e ir eliminando los obstáculos que suponen las diferencias normativas entre países, que dan lugar a distinto grado de protección del dinero público.

Palabras clave: fraude fiscal, OLAF, Hércules, Pericles.

Clasificación JEL: H26, H87, K34.

\section{Abstract}

This paper presents the challenges of the European Union in the fight against tax fraud. Although this goal has been pursuing for years, the creation of the European Anti-Fraud Office $(O L A F)$ in 1999 and the rising needs of budgets to counteract the effect of the current economic crisis, have intensified efforts to improve the controls, enhance cooperation between Member States and remove obstacles which results by differences in rules and practices in member countries due to different levels of protection of public money.

Keywords: fiscal fraud, OLAF, Hercules, Pericles.

JEL classification: $H 26, H 87, K 34$.

\section{Introducción}

Desde hace tiempo, la Unión Europea (UE) viene luchando contra el fraude fiscal aumentando la cooperación entre los Estados, compartiendo información, y creando un mecanismo de reacción rápida contra el fraude del IVA. Las rentas no declaradas por los ciudadanos suponen una reducción significativa de los ingresos fiscales nacionales, por lo que se hace cada vez más necesario mejorar la eficiencia y la eficacia en la recaudación de impuestos.

El fraude cuesta miles de millones a los contribuyentes y en muchos casos facilita las operaciones de la delincuencia organizada, que acaba deteriorando la confianza de los ciudadanos en las instituciones.

Ante estos hechos, era necesario reducir la brecha fiscal, es decir, el dinero que los Estados miembros dejan de ingresar debido al fraude, la evasión fiscal, y la ingeniería fiscal, aprovechando las lagunas en la legislación tributaria, los desajus- 
tes entre los sistemas fiscales y la escasa cooperación entre países. En la medida que se trata de un problema transfronterizo, las acciones unilaterales no son suficientes.

Tras la crisis internacional de 2008 y las duras consecuencias sobre las políticas económicas y sociales que sostenían los gobiernos, y ante la necesidad de disponer de más recursos para hacer frente a las demandas sociales, el fraude fiscal adquiere una nueva dimensión, después de décadas en las que los Gobiernos no habían tenido la sensibilidad suficiente ante estos casos.

Los graves problemas surgidos en los Estados miembros por el aumento del déficit público y de la deuda, han desembocado en situaciones límite que ha obligado a una drástica reducción del gasto y un aumento de la presión fiscal.

Las políticas de austeridad han obligado en cierto sentido a mejorar la capacidad de recaudar impuestos y han impulsado actuaciones desde la Comisión Europea para avivar la persecución del fraude, revisar las medidas que están en vigor, y coordinar más la lucha contra los que defraudan.

Pero para prevenir y disminuir el fraude y la evasión, los objetivos se deben plantear desde diferentes perspectivas, ahondando en el intercambio de información tanto entre los países europeos como con el resto del mundo. Estas iniciativas han sido impulsadas por el G20 y secundadas por la OCDE ${ }^{1}$.

La creciente globalización de las relaciones económicas internacionales ha propiciado que algunas multinacionales aprovechen las actuales condiciones para reducir su carga tributaria, erosionando las bases imponibles de muchos países al trasladar sus beneficios a otros de baja o nula tributación y en los que se desarrolla una escasa o nula actividad económica.

El problema de la «Erosión de bases imponibles y la transferencia artificial de beneficios empresariales» (BEPS siglas en inglés de Base Erosion and Profit Shifting), identificado en 2012, generó un gran malestar social y un importante perjuicio económico a gobiernos y empresas, lo que desató una importante reacción de los gobiernos más afectados.

Como resultado, la OCDE presentó en julio de 2013 un Plan de Acción que diagnosticaba los principales problemas de la BEPS, diseñaba posibles soluciones a los Estados para limitar los vacíos normativos existentes entre países que permitían ocultar beneficios,marcando unpunto de inflexión en la historia de la cooperación internacional en materia de tributación.

En la medida que el marco reglamentario estaba basado en el consenso y los efectos eran imprevisibles, había que adoptar una metodología de trabajo adecuada que asegurara buenos resultados.

El Plan, que recibió el respaldo del G20 en 2013, sería un punto de partida para avanzar en una Unión Fiscal o una armonización de bases imponibles en la UE que limitara la elusión de las obligaciones tributarias, no solo en el ámbito empresarial

\footnotetext{
${ }^{1}$ Boletín Económico de ICE núm. 3.046, del 1 al 31 de diciembre de 2013, p. 3 y ss.
} 
sino también en el de las personas físicas ${ }^{2}$. Aunque el mayor flujo monetario en movimiento correspondía a las empresas, algunos ciudadanos también realizaban prácticas para eludir la obligación fiscal y trasladar rentas a paraísos fiscales.

Por su parte, en junio de 2015 la Comisión Europea publicó una «lista negra paneuropea de paraísos fiscales en la que figuraban 30 países o territorios considerados como «no cooperativos» en materia de lucha contra el fraude y la evasión fiscal. Cuatro de ellos se encuentran en Europa (Andorra, Mónaco, Liechtenstein y la isla de Guernsey, en el canal de la Mancha, territorio dependiente de Reino Unido).

Sin embargo, la posición fragmentada de la UE contra los paraísos fiscales no ha permitido frenar la elusión fiscal practicada por multinacionales; no todos los países tienen una lista negra ni son todos los que adoptan medidas contra ellos. Una posición de la UE en su conjunto contra los paraísos fiscales reforzaría la lucha contra estos enclaves.

\section{Iniciativas europeas en la lucha contra el fraude. La Oficina Europea de Lucha contra el Fraude (Office Européen de Lutte Anti-Fraude. OLAF)}

Sobre las bases de su predecesora, la Unidad Europea de Lucha contra el Fraude (UCLAF, Unité de Coordination de Lutte Anti-Fraude), en 1999 la Comisión Europea inició su política contra el fraude y la corrupción con la OLAF${ }^{3}$.

Se trata de un órgano de cooperación entre las autoridades competentes de los Estados que coordina sus actividades contra el fraude. Aunque tiene un estatuto de independencia para su función de investigación, la OLAF es parte de la Comisión con un personal con gran experiencia en: investigación, servicios policiales y judiciales nacionales, en el análisis y la evaluación de informaciones, o en actividades de apoyo o desarrollo de políticas relativas a la lucha contra el fraude.

${ }^{2}$ El Plan de Acción incluía 15 medidas para combatir el problema de la evasión fiscal, las prácticas fiscales perjudiciales y la planificación fiscal agresiva por parte de las multinacionales. Dichas acciones eran: Acción 1: Hacer frente a los desafíos fiscales que plantea la economía digital. Acción 2: Neutralizar los efectos de los dispositivos híbridos. Acción 3: Reforzar las normas sobre transparencia fiscal internacional. Acción 4: Limitar la erosión de la base imponible vía deducción de intereses y otros pagos financieros. Acción 5: Incrementar la eficiencia de las medidas para contrarrestar las prácticas fiscales perjudiciales, teniendo cuenta la transparencia y la sustantividad. Acción 6: Impedir el abuso de los convenios para evitar la doble imposición (CDI). Acción 7: Evitar eludir deliberadamente la condición de establecimiento permanente. Acciones 8 a 10: Garantizar que los resultados en materia de precios de transferencia tengan correspondencia con la creación de valor (lo que incluye medidas relativas a intangibles, riesgos y capital, y otras operaciones de alto riesgo). Acción 11: Establecer métodos para la recopilación y análisis de datos sobre erosión de la base imponible, traslado de beneficios y medidas para abordar esta cuestión. Acción 12: Requerir a los contribuyentes que comuniquen sus mecanismos de planificación fiscal agresiva. Acción 13: Nuevo análisis de la documentación sobre precios de transferencia. Acción 14: Hacer más efectivos los mecanismos para la resolución de controversias (procedimientos amistosos). Acción 15: Desarrollar un instrumento multilateral para la aplicación de las medidas creadas.

${ }^{3}$ En la web (http://olaf.europa.eu) se recoge información sobre buenas prácticas, tipos de fraude y programas de formación. 
Entre sus objetivos destacan:

- Sensibilizar a la población sobre las consecuencias de la falsificación y el contrabando en la UE con indicaciones sobre cómo detectar una moneda de euro falsa.

- Desde la Comisión, informar con regularidad a sus gestores de proyectos, al personal financiero, a sus auditores y al personal de sus delegaciones sobre el riesgo de fraude y sobre procedimientos de actuación.

- La formación a funcionarios para compartir experiencias y novedades en investigación.

En la medida que el 85 por 100 del presupuesto de la UE es administrado por los Estados miembros (gestión compartida) y que la responsabilidad última de la prevención del fraude depende de cada uno de ellos, la OLAF impulsa la cooperación entre las autoridades nacionales para:

- Coordinar las legislaciones, las administraciones y las actividades a fin de proteger las finanzas de la UE.

- Establecer nexos entre las autoridades nacionales y la OLAF.

- Informar a la Comisión Europea cuando se descubran casos de fraude e irregularidades.

\subsection{Relación de la OLAF con otras instituciones}

La OLAF colabora con otras instituciones como:

- La Comisión de Control Presupuestario del Parlamento Europeo (COCOBU), revisando la legislación contra el fraude y otras irregularidades. La OLAF informa al Parlamento de sus actividades, aunque sin revelar información sobre las investigaciones en curso.

- El Tribunal de Cuentas Europeo, que controla las finanzas de la UE y ayuda al Parlamento Europeo y al Consejo a supervisar la ejecución del presupuesto mediante informes y dictámenes. El Tribunal examina si las operaciones financieras se han registrado debidamente y si se han ejecutado y gestionado legalmente. Finalmente, el Tribunal comunica a la OLAF cualquier sospecha de fraude o corrupción.

- También colabora con los 28 Estados miembros en distintos frentes para mejorar el intercambio de información y la coordinación entre administraciones nacionales.

- Con la Oficina Europea de Policía de la Unión Europea (Europol), que presta asistencia en los casos de falsificación de dinero y el impuesto sobre el valor añadido (IVA). La falsificación de euros cuesta cada año millones de euros a la 
UE y Europol estima que el fraude del IVA en los Estados miembros se aproxima a los 60.000 millones de euros anuales.

Europol también gestiona el proyecto de análisis del «fraude intracomunitario del operador desaparecido»o «fraude carrusel», sustracción del IVA perpetrada por delincuentes organizados. Se trata de la única base de datos europea que reúne información sobre este tema ${ }^{4}$.

$\mathrm{El}$ «fraude carrusel» se genera por las lagunas existentes en el actual régimen de tributación por IVA en las operaciones intracomunitarias, provocadas por la falta de una armonización tributaria plena entre los países de la UE. Como cada Estado aplica un tipo de IVA distinto y los países más importadores ven reducida su recaudación, se ha optado por un régimen transitorio, aplicable desde 1993, en el que se instaura la libre circulación de mercancías por la creación del Mercado Único Europeo, según el cual la empresa adquirente del producto importado que proceda de un país intracomunitario se autorepercute la cuota que correspondería a dicho producto, para simultáneamente poder deducírsela 5 .

En 2004, la OLAF y Europol firmaron un acuerdo de cooperación contra el fraude, la corrupción, o cualquier otro delito o actividad de la delincuencia organizada internacional que perjudique a los intereses financieros de la UE. Este permite compartir información, la cooperación en la evaluación de amenazas y el análisis de riesgo en casos de interés común, excluyendo el intercambio de datos personales.

- Eurojust, creado en 2002 y con sede en La Haya, se modificó por Decisión del Consejo, de 16 de diciembre de $2008^{6}$. Se trata de un centro de conocimiento y experiencia judicial cuya misión es aumentar la eficacia de las autoridades nacionales en la investigación y persecución de la delincuencia organizada y transfronteriza en la UE.

Eurojust coordina a las autoridades nacionales en sus investigaciones y en la persecución de los delitos, al mismo tiempo que resuelven problemas prácticos que surgen de las diferencias entre los sistemas legales de los Estados miembros. Cada país nombra a un representante en Eurojust, fiscales, jueces o funcionarios de policía con competencias equivalentes y de reconocida experiencia. También puede integrar a personal de países terceros con los que tiene un acuerdo de cooperación (casos de Noruega y Estados Unidos).

${ }^{4}$ El fraude intracomunitario del operador desaparecido, consiste en que un proveedor factura unas entregas y desaparece sin declarar ese IVA, pero dejando al cliente en posesión de una factura válida para deducción. De esta forma, la Hacienda no percibe el IVA por la entrega, pero debe permitir que el siguiente operador de la cadena deduzca el IVA soportado. Estos fraudes suelen organizarse en entregas en las que unos mismos bienes circulan varias veces de unos países a otros (fraude carrusel), perdiéndose por partida múltiple la cuota impositiva sobre un mismo producto.

5 Véase CAMARERO (2011).

${ }^{6}$ Las principales funciones y poderes de Eurojust aparecen enumeradas en la Decisión de Eurojust; por ejemplo, ayudar a las autoridades nacionales competentes de los Estados miembros en sus necesidades de cooperación y a petición de estas. Por su parte, Eurojust podrá solicitar a los Estados miembros que lleven a cabo una investigación o actuaciones judiciales sobre hechos concretos. 
Eurojust tramita unos 1.400 casos y celebra unas 140 reuniones de coordinación al año en las que se tramitan los asuntos y se planifican las acciones operativas que demandan las investigaciones, tales como detenciones o registros que hayan de ejecutarse de manera simultánea ${ }^{7}$.

Asimismo, ayuda en la resolución de conflictos de jurisdicción en los casos en que más de un Estado sea competente en una investigación o una actuación judicial, facilitando la ejecución de instrumentos jurídicos internacionales como la orden europea de detención. Por último, financia la creación y las necesidades operativas de los equipos de investigación.

- OLAF también se relaciona con Organismos Internacionales, Eurojustice, Interpol y Organización Mundial de Aduanas y, en terceros países, colabora con U.S. Customs and Border Protection y el FBI.

Aunque la OLAF no tiene competencias para enjuiciar a los delincuentes, asiste a los Estados y a las instituciones de la UE en la detección de irregularidades e en sus investigaciones. Igualmente, puede emprender investigaciones dentro de cualquier organización de la UE, los Estados miembros, u otros países a los que se destinan fondos de la UE.

\subsection{Los programas de OLAF}

La OLAF ha desarrollado dos programas en la lucha contra el fraude: Hércules, contra las irregularidades financieras, y Pericles, contra la falsificación de euros.

El programa Hércules. Creado en 2004, se centra en la lucha contra el fraude, la corrupción y otras actividades ilegales que repercuten negativamente en las finanzas de la UE, incluida la lucha contra el contrabando y la falsificación de cigarrillos.

Los programas Hércules I (2004-2006), Hércules II (2007-2013) y Hércules III (2007-2013) han venido ofreciendo:

- Formación y asistencia a asociaciones europeas de abogados, jueces y otros profesionales del derecho en la lucha contra el fraude.

- Asistencia técnica y apoyo informático a las autoridades nacionales.

- Subvenciones a las administraciones nacionales y regionales de los Estados miembros para la adquisición de equipo técnico avanzado (equipos de rayos $\mathrm{X}$, bases de datos y herramientas de investigación informáticas) destinado a reforzar la capacidad operativa de los servicios policiales.

${ }^{7}$ Las reuniones de coordinación se centran en casos concretos, en relación a los delitos considerados como prioritarios por el Consejo de la Unión Europea: terrorismo, narcotráfico, tráfico de seres humanos, fraude, corrupción, delito informático, blanqueo de capitales y otras actividades ilegales relacionadas con la presencia de grupos delictivos organizados en la economía. 
Gracias al programa Hércules se ha incrementado la cooperación y el intercambio de información, que ha tenido como resultado la incautación de grandes cantidades de cigarrillos, tabaco y otras mercancías de contrabando, la recuperación de grandes sumas de derechos de importación, IVA e impuestos especiales impagados, y el arresto y la condena de personas implicadas en el contrabando o en otras operaciones contra los intereses financieros de la Unión.

El programa Pericles (2007-2013). También administrado por la OLAF, está enfocado en la lucha contra la falsificación del euro a través de la formación y la asistencia técnica a las autoridades nacionales competentes, a funcionarios de policía y aduanas, a representantes de los bancos centrales y casas de moneda nacionales, a expertos jurídicos (como jueces y abogados), y a otros grupos profesionales en la materia.

\subsection{Procedimientos de la OLAF}

En su forma de proceder, en primer lugar la OLAF recibe información privada o pública sobre casos sospechosos, en muchas ocasiones de los responsables de la gestión de los fondos europeos (Gráfico 1).

\section{GRÁFICO 1}

DISTRIBUCIÓN DE LA INFORMACIÓN RECIBIDA DEL SECTOR PÚBLICO Y SECTOR PRIVADO

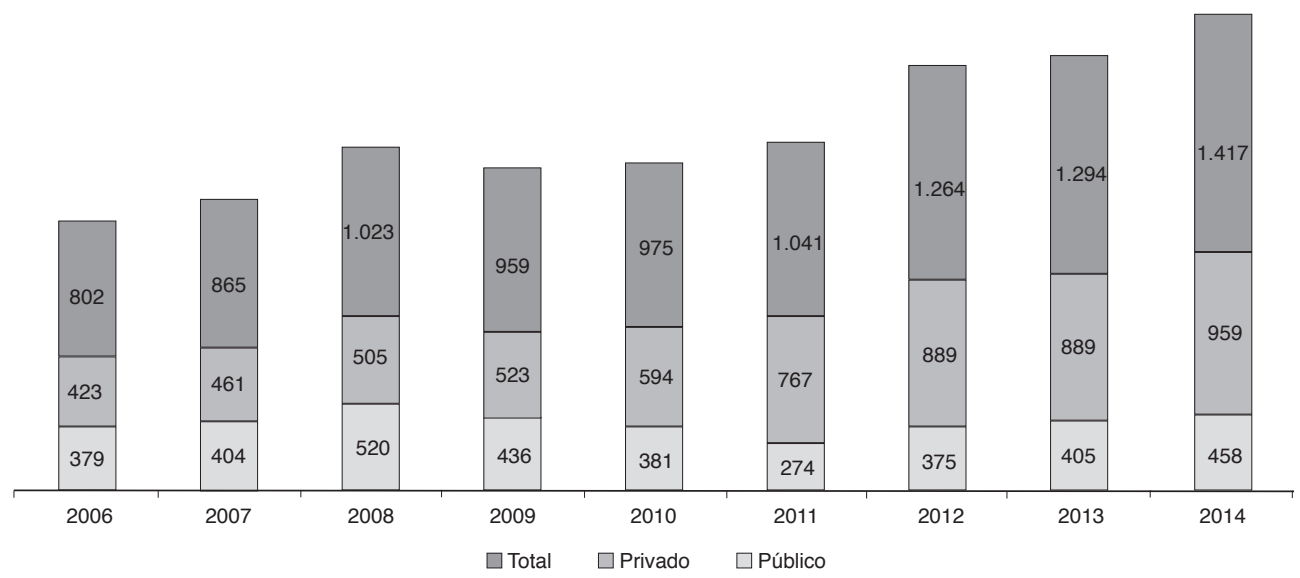

FUENTE: Elaboración propia a partir de los informes de la OLAF.

Las denuncias se evalúan por la Unidad de Investigación, Selección y Revisión, que dictamina sobre la apertura o desestimación del caso, dependiendo de si la información es competencia o no de la OLAF. Si el Director General decide que es suficiente y entra en el ámbito de las prioridades de investigación, se abre la fase de investigación. 
A continuación se realizan entrevistas, inspección de locales, controles sobre terreno, operaciones técnico-jurídicas, etc., verificándose la validez de las mismas y elaborando conclusiones, a partir de las cuales el Director General recomienda las medidas que se deben tomar: judiciales, disciplinarias, financieras o administrativas.

Los casos se clasifican en cuatro tipos:

- Investigación interna. Dentro de las instituciones y organismos de la UE con el objetivo de detectar fraudes, corrupción y cualquier ilegalidad que afecte a los intereses financieros de la UE. La OLAF se informa a través de las personas afectadas y cuando descubre la posibilidad de implicación de una persona (dirigente, funcionario o agente) se remite a la institución, órgano u organismo del cual forme parte la persona.

- Investigación externa. También son investigaciones administrativas. En este caso se realizan fuera de las instituciones y organismos de la UE para detectar fraudes u otras irregularidades por parte de personas físicas o jurídicas.

- Coordinación. Incluye los casos abiertos en los que la OLAF ayuda en las investigaciones que realizan las autoridades nacionales $\mathrm{u}$ otros departamentos de la UE, facilitando intercambio de información y de contactos.

- Asistencia penal. Cuando las autoridades competentes de un Estado miembro o un país tercero llevan a cabo una investigación penal con la asistencia de la OLAF.

El tiempo para ponerlas en práctica varía según el caso, siendo mayor si se requieren acciones legales o recuperación financiera. Esto suele suceder cuando el fraude es grave o de grupos de delincuencia organizada que utilizan métodos como la quiebra planificada, o rastros documentales de alta tecnología para ocultar sus activos.

Por último, se elabora un informe final que se remite a las instituciones, organismos, oficinas, agencias o Estados miembros afectados y se hace un seguimiento de la aplicación de las recomendaciones, que culmina con investigaciones penales, enjuiciamientos y condenas, recuperaciones financieras, o medidas disciplinarias.

La OLAF no se encarga de recuperar los fondos, sino que es responsabilidad de las instituciones de la UE y de los Estados miembros. 


\section{GRÁFICO 2}

\section{PROCEDIMIENTO DE LA OLAF}

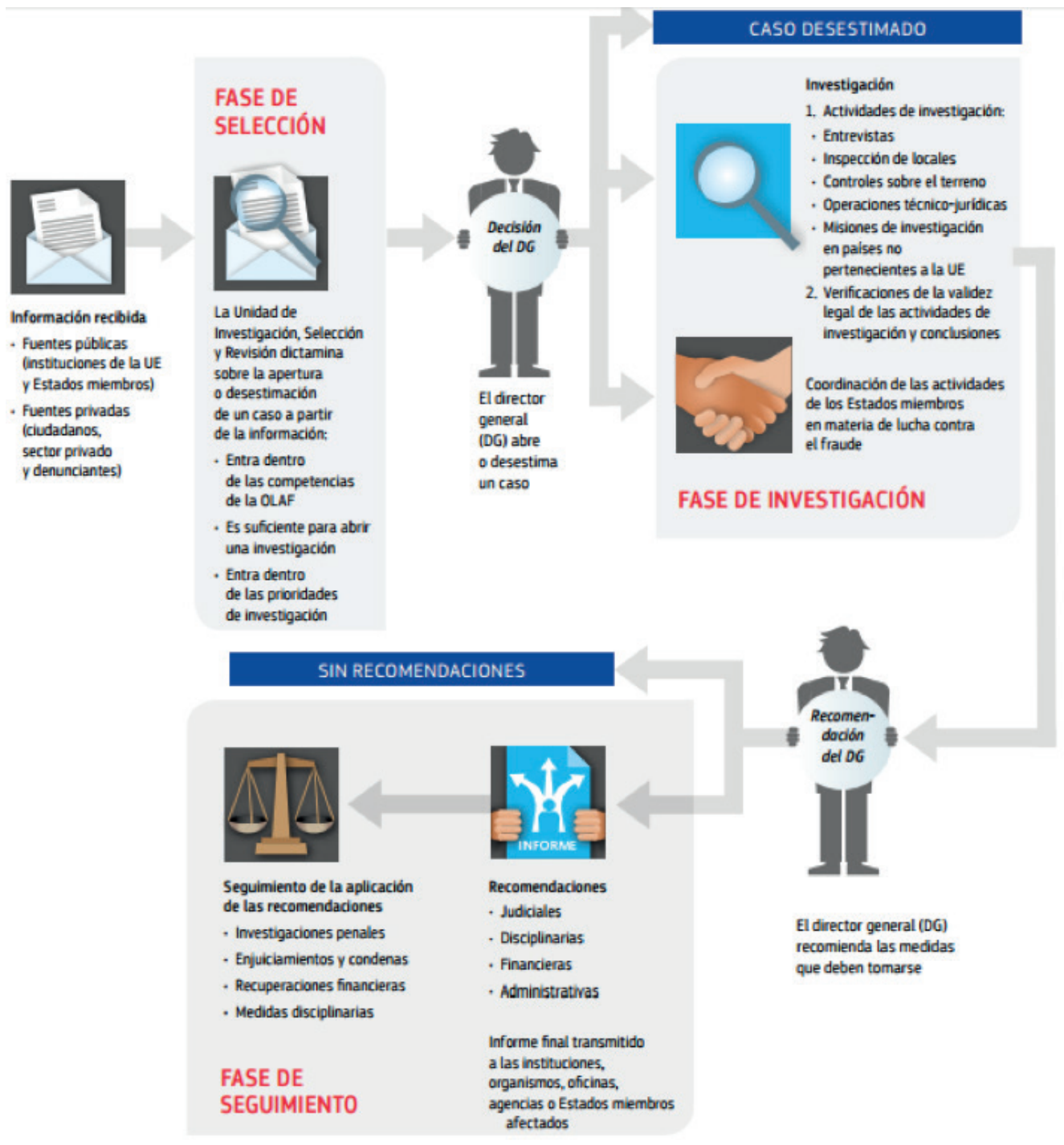

FUENTE: OLAF. 
Para velar por esta independencia operativa se establece un Comité de Vigilancia, compuesto por cinco personas externas, nombradas de común acuerdo por el Parlamento, el Consejo y la Comisión.

Algunos ejemplos (Gráfico 3) de las investigaciones que realiza la OLAF son sobre:

- El uso irregular de fondos de la UE destinados a proyectos, como la ayuda exterior, la agricultura, el medio ambiente, etc.

- El impago de derechos de aduana y evasión fiscal de los importadores.

- Falsificación de dinero.

- El contrabando de cigarrillos por delincuentes organizados.

- La financiación de productos agrícolas inexistentes (árboles frutales declarados que nunca llegaron a plantarse, etc.).

- Las irregularidades en procedimientos de licitación (subastas).

- La filtración de preguntas de exámenes de selección y de modelos de respuesta.

\section{GRÁFICO 3}

INFORMACIÓN POR SECTORES, 2014

(En millones de euros)

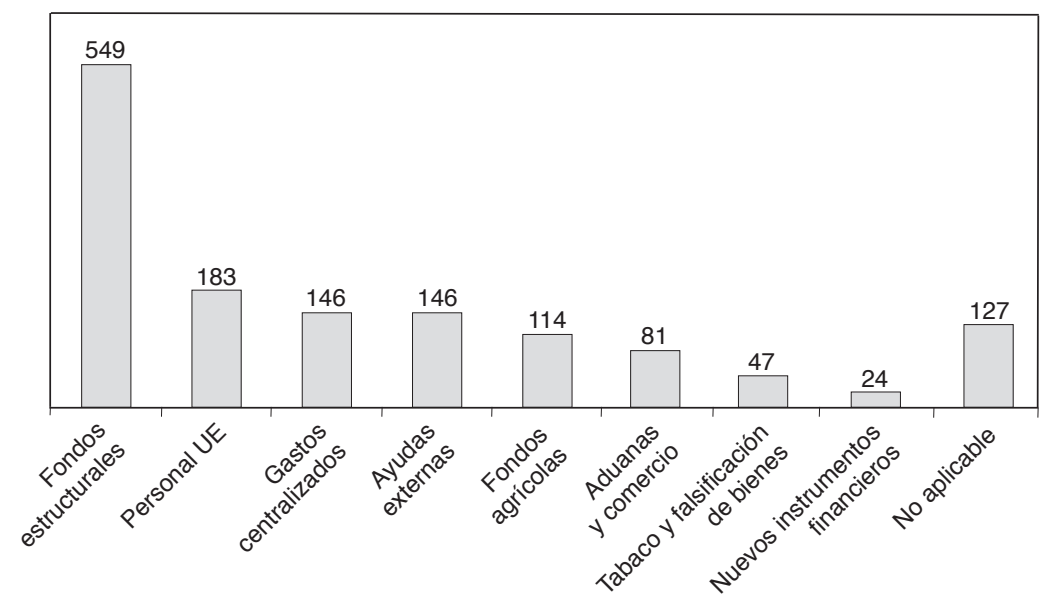

FUENTE: OLAF.

Desagregado por países, la incidencia de las investigaciones varía de forma significativa, según se puede apreciar en el Gráfico 4 . 


\section{GRÁFICO 4}

INFORMACIÓN RECIBIDA DE LOS ESTADOS MIEMBROS, 2014

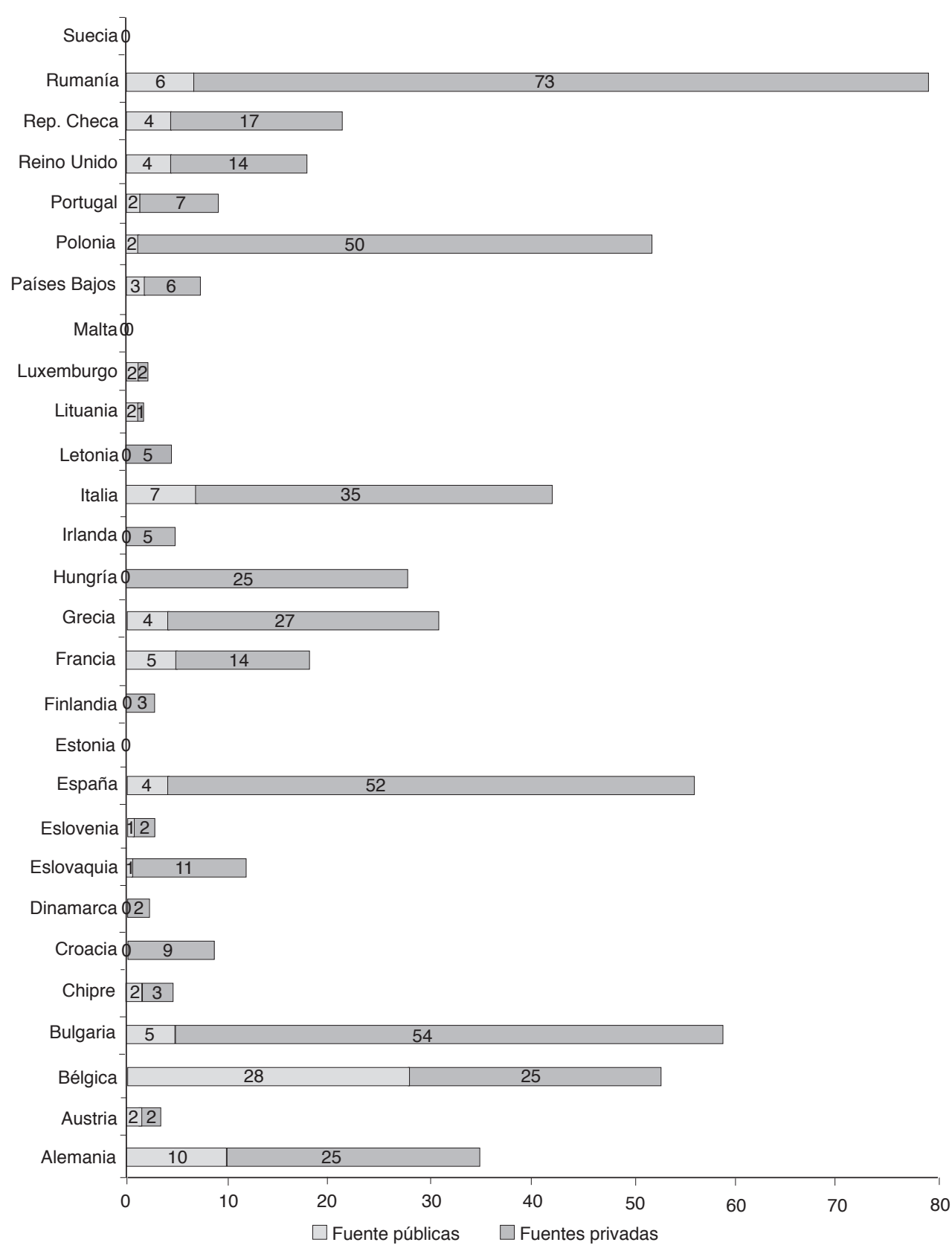

FUENTE: OLAF. 


\section{Medidas complementarias en la lucha contra el fraude en la Unión Europea}

Los avances de la tecnología constituyen un reto para los servicios policiales y los responsables de la lucha contra el fraude, en la medida que los defraudadores desarrollan nuevas y sofisticadas para mantener un «negocio» muy lucrativo.

Como hemos comentado anteriormente, la función de la OLAF en la investigación, la asistencia, y en la mayor comunicación entre autoridades y servicios policiales y de ayuda técnica, es hoy más importante que nunca.

La Comisión sigue profundizando en su lucha contra el fraude con una estrategia centrada en:

- Las acciones estructurales de sus Fondos y otros servicios de la Comisión como las políticas de investigación.

- Medidas específicas en función de los datos disponibles.

- En utilizar el potencial de la tecnología, donde Pluto y el Sistema de Información Antifraude son dos frentes claves activados.

3.1. El Proyecto Pluto, basado en la experiencia operativa de la OLAF, arranca para apoyar a la Dirección General de la Sociedad de la Información de la Comisión y mejorar sus capacidades de auditoría y funciones de control, a través de potentes herramientas de análisis e información sobre los indicadores de fraude. Con este enfoque ha sido posible detectar muchos más casos de presuntas irregularidades.

Pluto pone énfasis en el gran interés de las tecnologías de la información para atrapar a los defraudadores. Entre otras cosas, permite agilizar el proceso de detección de anomalías con una plataforma técnica única para el intercambio seguro de datos entre las aduanas y otras autoridades nacionales.

3.2. Asimismo, el Servicio de Coordinación Antifraude (AFCOS) refuerza las el intercambio de información entre la OLAF y los Estados miembros creando AFCOS nacionales. La OLAF asiste y asesora a los Estados miembros en la aplicación de esta nueva forma de cooperación con órganos policiales y judiciales de la UE y de terceros países.

Las competencias de los AFCOS nacionales varían en función del país, destacando:

- Dirigir la creación y puesta en marcha de las estrategias nacionales y promover los cambios legislativos y administrativos necesarios para proteger los intereses financieros de la UE.

- Identificar las posibles deficiencias de los sistemas nacionales para la gestión de fondos de la UE.

- Coordinar e informar sobre irregularidades y sospechas de fraude entre las instituciones nacionales y la OLAF.

- Mejorar la formación en la prevención y lucha contra el fraude. 
3.3. En otro orden, el 17 de julio de 2013 la Comisión adoptó una propuesta de Reglamento sobre la creación de una Fiscalía Europea (EPPO).

La Fiscalía Europea tendría el mandato de investigar, perseguir y llevar a juicio los delitos que afectan a los intereses financieros de la UE y garantizar que se actúe con eficacia, y de forma independiente y armonizada.

De acuerdo con la propuesta, la Fiscalía Europea constaría de un nivel centralizado con fiscales europeos, y de otro nivel descentralizado con fiscales europeos delegados en los Estados miembros.

Las competencias de la Fiscalía Europea estarían equilibradas por los derechos de la defensa garantizados por las legislaciones nacionales de los Estados miembros, la legislación de la UE y la Carta de los Derechos Fundamentales.

3.4. La Asistencia Administrativa Mutua (AAM) se establece con propuesta de modificación del Reglamento (CE) núm. 515/97. El 25 de noviembre de 2013, la Comisión lanzó posibles mejoras en la detección y la lucha contra el fraude aduanero y la disponibilidad de datos, abordando las ineficiencias del doble control de la protección de datos, garantizando la admisibilidad de las pruebas en los procesos judiciales de los Estados miembros, y reforzando la confidencialidad de los datos.

\section{Otras iniciativas para combatir el fraude en la UE}

La Comisión Europea ha lanzado propuestas paralelas para luchar contra el fraude en tres frentes:

- Nacional. Mejorando la capacidad administrativa de los Estados para recaudar impuestos con el apoyo técnico que necesiten. El programa de la UE de la ventanilla única haría más fácil el pago de impuestos.

- En la UE. Reforzando las medidas existentes con el establecimiento de un número de identificación fiscal europeo transfronterizo, un mecanismo de reacción rápida contra el fraude del IVA, normas mínimas y multas comunes.

- Con terceros países. Aplicando normas equivalentes a las de la UE para que la lucha contra la evasión fiscal sea efectiva, regulando las operaciones con paraísos fiscales y con medidas eficaces para reducir las lagunas fiscales existentes entre los países.

En esta línea, la UE ha adoptado decisiones de gran interés entre las que podríamos destacar:

4.1. La Directiva de la Fiscalidad del Ahorro (Directiva 2003/48/CE del Consejo, de 3 de junio de 2003), en la que se regula el intercambio de información automático sobre los intereses percibidos por personas físicas entre los Estados miembros, se aprobó en 2003 pero no se aplicó hasta julio de 2005, cuando se consiguió una 
«condicionalidad externa», extendiendo los acuerdos a cinco países de Europa no miembros de la UE (Suiza, Liechtenstein, Mónaco, Andorra y San Marino) y los diez territorios del Caribe ${ }^{8}$. Su contenido permitía que un país pudiera reunir datos sobre el ahorro de personas que no fueran residentes y transmitirlos a las autoridades del lugar de residencia. Fue un avance contra el secreto bancario en la medida que las haciendas tendrían información en tiempo real de los rendimientos obtenidos en otros países por cualquier tipo de inversión.

Luxemburgo y Austria la estuvieron bloqueando para no verse en desventaja frente a otros centros financieros. Con las recomendaciones del G20, ambos países suavizaron sus posiciones.

En diciembre de 2014, el Consejo adoptó la Directiva 2014/107/UE que modificaba las disposiciones sobre obligatoriedad del intercambio automático de información entre administraciones tributarias y extendía su aplicación a los intereses, dividendos y otros tipos de rendimientos.

Entró en vigor a 1 de enero de 2016 y enlaza con las actuales tendencias de lucha contra el fraude fiscal internacional a través de la articulación de mecanismos de transparencia y asistencia mutua, superando los antiguos estándares de confidencialidad y secreto bancario frente a las autoridades fiscales. Por tanto, comenzarán a intercambiarse automáticamente datos sobre la obtención de rentas del ahorro por personas físicas residentes en la UE.

Se trataba de combatir la proliferación de la ingeniería fiscal en empresas, con actuaciones y calendarios concretos, tratando de cerrar las fisuras por las que se escapaban miles de millones de euros.

Los 28 Estados miembros han adoptado por unanimidad tal modificación, así como los cinco grandes centros financieros europeos (no UE) que asumían medidas similares. La nueva disposición acaba con el régimen de coexistencia (intercambio de información/retención en la fuente), y los Estados miembros que habían aplicado tal mecanismo (retención en la fuente), Austria y Luxemburgo, aceptaron el cambio.

El ámbito de aplicación de la Directiva 2014/107/UE es, en general, más amplio que el de la Directiva 2003/48/CE y se dispone que en caso de coincidencia de ámbitos de aplicación, prevalece la Directiva 2014/107/UE.

Asimismo, suponía la aplicación de una norma única internacional elaborada por la OCDE para el intercambio automático de información, que fue apoyada por el G20 en septiembre de 2014.

Con la nueva Directiva, los dividendos, las plusvalías de capital y otras formas de ingresos financieros, y los saldos de cuentas, se añadirán a la lista de categorías que ya están sujetas a intercambio automático de información en la UE (ahorros, rendimientos del trabajo, remuneración de directivos, seguros, pensiones y viviendas y rendimientos inmobiliarios). En definitiva, se aspiraba a conseguir una transparencia

${ }^{8}$ Diez territorios dependientes o asociados del Reino Unido y de los Países Bajos: Anguila, Aruba, las Islas Vírgenes Británicas, las Islas Caimán, Guernesey, la Isla de Man, Jersey, Montserrat, las Antillas Neerlandesas y las Islas Turks y Caicos. 
tributaria completa en Europa y acabar con el secreto bancario a través de una cooperación cada vez más estrecha contra los evasores fiscales.

4.2. En el contexto de la lucha contra la corrupción, la Comisión adoptó el 6 de junio de 2011 la Decisión C (2011) 673 Final, por la que se establece el «mecanismo de información para la evaluación periódica de la anticorrupción de la UE» o «Informe Anticorrupción de la UE», que se inserta también en la política de lucha de la Unión contra este problema.

El primer Informe de la UE sobre la Lucha Contra la Corrupción se publicó en febrero de 2014, en el que se recogía la situación de cada país (medidas que se aplicaban, posibles mejoras, etcétera), recalcando en su contenido la gran cantidad de iniciativas emprendidas en cada uno de ellos pero con resultados muy desiguales. Por último, se recomendaba intensificar el trabajo para evitar y castigar la corrupción con más compromisos por parte de los Estados. El Informe se publicaría cada dos años.

El Informe centra en:

- Evaluar periódicamente la situación de la UE y sus Estados miembros en la lucha contra la corrupción.

- Analizar las tendencias en la corrupción y sus causas, así como la identificación de buenas prácticas y su puesta en común, promoviendo la integridad, la obligación de rendir cuentas, y la debida gestión de los asuntos y bienes públicos.

- Adoptar recomendaciones para ajustar mejor la política de la Unión sobre prevención y lucha contra la corrupción, así como el fortalecimiento de las normas existentes.

- Asesorar a los Estados miembros en estos temas con más asistencia técnica.

- Servir como un instrumento de ayuda a los Estados miembros, a organizaciones y asociaciones involucradas en combatir la corrupción, y a la sociedad civil en su conjunto para identificar deficiencias en la materia y aumentar la sensibilización y la formación en la lucha contra ella.

- Fomentar la cooperación internacional y la asistencia técnica en la prevención y la lucha contra la corrupción.

- Prevención, criminalización y medidas para imponer el cumplimiento de la ley.

- Recuperación de capital ilegal.

- Intercambio de información.

El Informe Anticorrupción no es un mecanismo novedoso contra la corrupción, aunque su procedimiento de elaboración y contenido se adapte específicamente a la UE y a sus Estados miembros. Existían ya otros Informes de este tipo elaborados por el Consejo de Europa o Transparencia Internacional.

4.2.1. La Convención de las Naciones Unidas contra la Corrupción (UNCAC), también conocida como la Convención de Mérida, entró en vigor el 14 de diciem- 
bre de 2005 al reunir las 30 ratificaciones requeridas. Actualmente la integran 126 Estados.

Se trata del único Convenio universalmente vinculante, fundamental en la lucha contra el fraude, y una herramienta vital para ofrecer una respuesta general a un problema global.

En este sentido, la Convención reconoce que una función pública eficiente y transparente es la base de un buen gobierno. Asimismo, la recuperación de activos se consideraba fundamental, ya que esos fondos son propiedad de los Estados y era indispensable su devolución a los países de los que fueron sustraídos, lo que obligaba a los Estados firmantes a cooperar más.

4.2.2. Por su parte, el Convenio OCDE contra la corrupción funciona desde 1997, cuando sus miembros adoptaron el Convenio de Lucha contra la Corrupción de Agentes Públicos Extranjeros en las Transacciones Comerciales Internacionales (conocido como «Convenio Anticohecho»), que junto a la Recomendación revisada de 2009 para reforzar la lucha contra la corrupción de funcionarios públicos extranjeros en las transacciones comerciales internacionales y sus Anejos (Guías de buenas prácticas), y la Recomendación de 2009 sobre medidas fiscales para reforzar la lucha contra la corrupción de funcionarios públicos extranjeros en las transacciones comerciales internacionales, conforman los instrumentos de los que dispone la OCDE para combatir la corrupción de los agentes públicos extranjeros, considerando el «blanqueo» como delito conectado con la corrupción.

El Convenio recoge para los países cuatro aspectos:

- Penal: Con la obligación de definir como delito y castigar el cohecho realizado para la obtención de algún contrato internacional.

- Contable: Establece recomendaciones a las empresas para prevenir el encubrimiento de algunos gastos en los registros contables.

- Blanqueo de dinero: Con pagos relacionados con transacciones internacionales.

- Asistencia legal mutua: Los países están obligados a dar apoyo legal oportuno y establecer provisiones sobre la extradición.

También pretende asegurar una libre competencia no viciada por la corrupción, así como el compromiso de los países para introducir las modificaciones legales que castiguen los sobornos a funcionarios públicos extranjeros realizados por sus nacionales.

4.2.3. Por último, el Grupo de Estados contra la Corrupción (GRECO) se constituyó en 1999 en el ámbito del Consejo de Europa, con la finalidad de controlar el cumplimiento por los Estados de las normas anticorrupción adoptadas para mejorar la capacidad de lucha contra la corrupción. Se trata de un grupo abierto a cualquier país y no limitado a los miembros del Consejo de Europa. 
GRECO realiza evaluaciones periódicas de cada Estado miembro en las que se analizan aspectos concretos, ofreciendo posibles soluciones con reformas legislativas o institucionales. Posteriormente, se concede un plazo de 18 meses al país evaluado para dar respuesta al mismo. Por último, GRECO hace una nueva evaluación relativa a la adopción o no de las soluciones demandadas.

Es pronto, para calibrar los resultados del Informe Anticorrupción, de su funcionamiento, y de su eficacia real; sin embargo, es posible que las observaciones y recomendaciones contenidas en el Informe puedan ser objeto de más atención por parte de los Estados de la que se ha venido prestando a otro tipo de informes de carácter más general.

Por último, hay que resaltar el hecho de que parte de la gestión del Informe Anticorrupción ha sido externalizada a través de una consultora privada.

\section{Conclusiones}

Para evitar a los evasores de impuestos, la UE avanza hacia la coordinación entre los países miembros mediante el cruce de datos y un intercambio automático de información.

En este sentido, cada Estado dejará de decidir si una determinada resolución fiscal puede ser relevante para otro país y, por el contrario, todos estarán obligados al intercambio automático de información sobre sus resoluciones fiscales.

De esta manera, se podrán detectar prácticas fiscales abusivas y tomar medidas. Asimismo, el canje de datos fomentará una competencia fiscal más leal en cada país, ya que las autoridades tributarias podrán cada vez menos ofrecer tratamientos fiscales selectivos ya que estas actuaciones estarían controladas por sus homólogos. Esta cooperación entre Estados miembros se ha extendido a otros países de fuera de la UE, basándose en acuerdos internacionales en la lucha contra los delitos fiscales.

Dentro de la Comisión, la OLAF, órgano de cooperación entre las autoridades competentes de los Estados y que coordina sus actividades, ha sido uno de los pilares en el desarrollo de políticas contra el fraude.

La UE está participando activamente en la implantación de un sistema multilateral de transferencia de información fiscal no solo a través las Directivas de la fiscalidad del ahorro y de cooperación administrativa, sino extensiva a la imposición indirecta, IVA e impuestos.

Se ha desarrollado una red de acuerdos de colaboración con otras instituciones que, sin duda, reforzarán, ampliarán y mejorarán el intercambio de datos y la colaboración a distintos niveles.

Las Directivas 2011/16/EU y 2014/107/EU han sido la respuesta a los problemas que plantea el fraude dentro de la Unión, siguiendo la línea de los acuerdos dentro del G20 y la OCDE sobre el tema.

Sin embargo, tanto el Parlamento como la Comisión reclaman más avances en esos frentes, lo que redundaría en un incremento de la recaudación y la consolidación de sistemas tributarios más justos. 


\section{Referencias bibliográficas}

[1] AEAT (2010). «La gobernanza fiscal y la presidencia de la UE 2010. Memoria de las actuaciones de la Agencia Tributaria relacionadas con la presidencia». Boletín Económico de ICE, 2996, 21-29.

[2] CALDERÓN, J. M. (2013). «La estrategia europea de lucha contra el fraude y la evasión fiscal: el plan de acción de la Comisión UE y sus principales implicaciones». Revista de Contabilidad y Tributación (CEF), 363, 5-40.

[3] CAMISÓN, J. A. (2013). «El Informe Anticorrupción de la Unión Europea». Teoría y Realidad Constitucional, 32, 373-388.

[4] CAMARERO, J. (2010). «El "fraude carrusel" en el Impuesto sobre el Valor Añadido. Modalidades y propuestas para erradicarlo». Cuaderno de Formación, 11, 49-63.

[5] CARRERAS, O. y MIGUEL, S. de (2013). «La relevancia de las libertades comunitarias en relación con las medidas de lucha contra el fraude fiscal». Crónica Tributaria. Boletín de Actualidad, 4, 13-20.

[6] COMISIÓN EUROPEA (2015). Comprender las políticas de la Unión Europea: La lucha de la UE contra el fraude y la corrupción. Luxemburgo.

[7] CUESTA, J. L. de la (2001). «El fraude en materia de ingresos de la Unión Europea y su tratamiento por el derecho penal español», en G. Quintero y F. Morales (eds.), El nuevo Derecho Penal español. Estudios en Memoria del Profesor José Manuel Valle Muñiz. Navarra, Aranzadi.

[8] CRUZ, M (2005). "El intercambio de información y el fraude fiscal. Nuevas tendencias en economía y fiscalidad internacional». Revista Información Comercial Española, 825, 173-186.

[9] FUENTES, M. (2015). Combatir la corrupción y legislar en la Unión Europea. Madrid, Marcial Pons.

[10] GIL, A. (2012). «La lucha contra el fraude fiscal comunitario: nuevas perspectivas», en J. J. Hinojosa (ed.). Medidas y procedimientos contra el fraude fiscal. Barcelona, Atelier.

[11] GONZÁLEZ,A. (2013). «La crisis económica y financiera de la Unión Europea y el Impuesto sobre las Transacciones Financieras. Su contribución al objetivo de estabilidad». Crónica Presupuestaria, 1.

12] LÓPEZ, C. M. (2012). «La lucha contra el fraude fiscal en el Derecho de la Unión Europea», en J. J. Hinojosa (ed.), Medidas y procedimientos contra el fraude fiscal. Barcelona, Atelier.

[13] MARTÍNEZ,L.A. (2012). «El fortalecimiento de la obtención de información tributaria en el ámbito internacional: FATCA “versus” RUBIK». Quincena Fiscal, 19, 37-79.

[14] MARTÍNEZ,E. (2013). «Avances de la Unión Europea en la lucha contra el fraude y la evasión fiscal. El intercambio automático de información». Boletín Económico de ICE, 3046, 3-18.

[15] MERINO. M del P y NOCETE, F. J. (2011). «El intercambio de información tributaria: entre la diversidad normativa, la imprecisión conceptual y la pluralidad de intereses». Crónica Tributaria, 139, 139-163.

[16] OECD (2013). Addressing Base Erosion and Profit Shifting. París, OECD Publishing.

[17] OECD (2013). Action Plan on Base Erosion and Profit Shifting. París, OECD Publishing. 
[18] OLAF (varios años). Annual Report Luxembourg. Publications Office of the European Union.

[19] RIBES, A. (2009). «Reflexiones en torno a la propuesta de nueva directiva comunitaria sobre la asistencia mutua en materia recaudatoria». Quincena Fiscal, 15, 69-90.

[20] SAMPLÓN, R. (2007). «Los paraísos fiscales y la lucha contra el fraude fiscal». Cuadernos de Formación. Instituto de Estudios Fiscales, 3.

[21] SÁNCHEZ, M. E. (2011). El intercambio de información tributaria entre Estados. Barcelona, Bosch.

[22] TOVILLAS, J. M. (2013). «La dimensión aplicativa de la Directiva comunitaria de intercambio de información tributaria». Quincena Fiscal, 10 (BIB 2013/1002).

[23] VILLAVERDE, M. B. (2013). «Medidas antifraude y buena gobernanza fiscal en la UE. Otro intento más de lucha contra los 'paraísos fiscales». Boletín CeDe UsC, marzo. 